\title{
PHYSICO-CHEMICAL STUDIES OF DISAZO DYES DERIVED FROM P. AMINOPHENOL ON SYNTHETIC POLYMER-FIBRES
}

\author{
J. O. OTUTU, D. OKORO AND E. K. OSSAI
}

(Received 1 December 2008; Revision Accepted 31, March 2010)

\begin{abstract}
The physico-chemical properties of a series of disazo dyes derived from $\mathrm{p}$-aminophenol on polyester and nylon 6 substrates are described. It was found that the dyes generally have higher affinities for the polyester fibre than for the nylon 6 fibre. The values of $\Delta \mu^{\circ}, \Delta \mathrm{H}^{\circ}$ and $\Delta S^{\circ}$ in the two dye-fibre systems suggest that the hydrogen bonding mechanism is operative in the dye-fibre binding forces.
\end{abstract}

KEYWORDS: Disazo dyes, diffusion coefficient, Activation energy, polyester and nylon 6 fibres.

\section{INTRODUCTION}

Dyeing is a process not only of mass transfer but also one in which interactions in different degree between dye and substrate take place. Thus the inclusion of thermodynamic sorption data is essential (Venkataraman, 1974; Anna et al., 2007). The application of physical chemistry to dyeing process led to the concept of "dyeing affinity". That is the free-energy change accompanying dye adsorption process, as a measure of the strength of dye-fibre bonding (Bird and Boston, 1975; Abrahavt, 1977). In a study involving a fabric blend (Kan et al., 1998), the kinetics of dyeing process was reported of polypropylene/polyester fibres blends using disperse dye C.I. Disperse Blue 56. Wherein the dye uptake, dyeing rate constants, diffusion coefficients and activation energy of Polypropylene/polyethylene terephthalate (PP/PET) blend fibres were defined.

The standard heat of dyeing, $\Delta H^{\circ}$ represents the total change in enthalpy of the system during dyeing as a result of molecular interactions at any point within the system. Both the solution phase and the fibre phase contribute to $\Delta \mathrm{H}^{\circ}$. And from the values of $\Delta \mathrm{H}^{\circ}$, one hopes to learn something of the values of the forces of attraction between dyes and fibres and the manner in which these forces of attraction are influenced by the chemical structure of the dyes and the fibre, since $\Delta \mathrm{H}^{\circ}$ is influenced by every single molecular interaction both in the solution and in the fibre phases (Mcgregor, 1967; Otutu et al., 2007). Similarly, the standard entropy of dyeing $\Delta S^{\circ}$, is a much more subtle aspect of the dyeing process that have to do with the ordering or the dispersal of molecules within the system.

Although, many papers describe the physicochemical studies of monoazo dyes and other dye types on cellulose, proteins and polyamide fibres and to some extent on polyester fibres (Peter, 1975; Otutu, 2006). Very few comparable investigations have been made with disazo disperse dyes on synthetic polymer-fibres (Venkataraman, 1974; Otutu et al., 2008). In this present study, the physico-chemical studies of disazo dyes derived from $\mathrm{p}$-aminophenol recently prepared by our research group is described. We also described the kinetics of the dyes on nylon 6 fibre. In another study (Kim et al., 2007), the thermodynamic adsorption parameters of 1,4 - diaminoanthraquinone on polyethylene terephthalate using several alkane media ranging from pentane to dacane was reported. They found that in the range from pentane to decane, as the number of carbon atoms in the alkane decreased, the standard affinity $\left(-\Delta \mu^{0}\right)$ increased. Also the diffusion coefficient (D) of the dye decreased and the activation energy $\left(E_{D}\right)$ increased with increasing number of carbon atoms in the alkane.

\section{EXPERIMENTAL SECTION \\ Preparation of dye dispersion:}

The previously prepared dyes (Otutu et al, 2008) were formulated to be applied to PET and nylon 6 fabrics. The composition of the dye dispersions comprised dispersing agent, Diwatex 40P (moderately sulphonated Kraft lignin, $20 \%$ on the weight of the dye) and $\mathrm{N}, \mathrm{N}$-dimethylformamide (DMF). The dispersions were prepared by dissolving each dye $(0.40 \mathrm{~g})$ in $8 \mathrm{~mL}$ of DMF and adding dispersing agent to the mark $(100 \mathrm{~mL})$.

\section{Determination of standard affinity, heat of dyeing and entropy of dyeing.}

Nine tightly closed test-tubes were placed in a thermostated dyebath-set at $363 \mathrm{~K}$ and $373 \mathrm{~K}$ respectively. Ten milliliters of dye liquor was placed in each test-tube to give 10 percent shade with a liquor ratio 80:1. Absorbance readings were taken on a camspsec spectrophotometer. $0.04 \mathrm{~g}$ of polyester (terelyene) fabric $(100 \%)$ sample obtained from Multichem (Nigeria) which was not pretreated was placed in each test-tube and covered. Timing started when the temperature of the dye liquor equilibrated with the dyebath and the bath was left to stand for six hours. After, the concentration of dye, $[\mathrm{C}]_{\mathrm{s}}$, remaining in the

J. O. Otutu, Department of Chemistry, Faculty of Science, Delta State University, Abraka, Nigeria

D. Okoro, Department of Chemistry, College of Science, Federal University of Petroleum Resources, P.M.B 1221, Effurun, Delta State, Nigeria.

E. K. Ossai, Department of Chemistry, Faculty of Science, Delta State University, Abraka, Nigeria 
dyebaths was measured in a $10 \mathrm{~mm}$ cell by the spectrophotometric method. The dyed samples were rinsed thoroughly with deionised water. The above procedure was repeated for the dyeing of nylon 6 fabrics at $353 \mathrm{~K}$, and $363 \mathrm{~K}$ respectively at $\mathrm{pH} 4$, adjusted with $2 \%$ acetic acid.

The standard affinity $\Delta \mu^{\circ},(\mathrm{J} / \mathrm{mol})$ measured at 363k and 373k was calculated using Eqn 1(Giles, 1974)

$$
\Delta \mu^{0}=-R T \ln \frac{[C]_{f}}{[C]_{s}}
$$

Where $\mathrm{R}$ is the gas constant $(8.317 \mathrm{~J} / \mathrm{mol} \mathrm{K}), \mathrm{T}$ the absolute temperature $(\mathrm{K}),[\mathrm{C}]_{\mathrm{f}}$ the concentration of the dye on the fibre at equilibrium $(\mathrm{g} / \mathrm{kg}),[\mathrm{C}]_{\mathrm{s}}$, the concentration of dye in the dyebath at equilibrium $(\mathrm{g} / \mathrm{L})$.

The heat of dyeing $\Delta \mathrm{H}^{\circ}(\mathrm{J} / \mathrm{mol})$ was calculated in accordance with Eqn 2(Bird and Boston, 1975).

$$
\Delta H^{0}=\frac{T_{2} \Delta \mu_{1}^{0}-T_{1} \Delta \mu_{2}^{0}}{T_{2}-T_{1}}
$$

Were $T_{1}$ and $T_{2}$ are the absolute temperatures 1 and 2 and $\Delta \mu^{\circ}{ }_{1}$ and $\Delta \mu^{\circ}{ }_{2}(\mathrm{~J} / \mathrm{mol})$ are the standard affinities at $\mathrm{T}_{1}$ and $\mathrm{T}_{2}$ respectively.

Finally, Eqn 3 was used to find the entropy of dyeing, $\Delta \mathrm{S}^{\circ}(\mathrm{J} / \mathrm{mol})$

$$
\Delta \mu^{o}=\Delta H^{\circ}-T \Delta S^{\circ}
$$

\section{Determination of diffusion (Sorption) coefficient and Activation energy of diffusion.}

Nine identical dyebaths (round bottomed flasks) were prepared and eleven $0.05 \mathrm{~g}$ nylon 6 fabric samples were used. Dye dispersion was placed in each flask to give 20 percent shade at a liquor ratio 20:1. The dyeing system was maintained at $\mathrm{pH} 4.0$ using $2 \%$ acetic acid.
The nylon 6 fabrics were entered into each flask. The flasks were placed in a thermostated dyebath set at $343 \mathrm{~K}$ and $353 \mathrm{~K}$ respectively. Timing started when the temperature of the dye liquor equilibrated with that of the dyebath, and a fabric sample was removed from the dyebath at intervals of $10 \mathrm{~min}$ and the last sample was removed after six hours of dyeing. Each dyed sample was washed with warm water and allowed to dry at room temperature. The absorbances of the dyes were measured after striping the dyed fabric samples with formic acid at $\lambda_{\max }(400 \mathrm{~nm})$ in a $10 \mathrm{~mm}$ quartz absorption cell campsec uv/vis spectrophotometer. The absorbance at $10 \mathrm{~min}$ intervals were $[\mathrm{C}]_{\mathrm{t}}$, and the absorbance after six hours of dyeing were $[\mathrm{C}]_{\infty}$. All measurements of dye solution were conducted at room temperature and graphs of $\mathrm{C}_{t} / \mathrm{C}_{\infty}$ against $t^{1 / 2}$ were plotted from where the slopes were obtained. The diffusion coefficients (D) were calculated using Eqn 4 (Yakubu, 2000).

$D=\left[\frac{C_{t}}{C_{\infty}}\right] \frac{\pi r^{2}}{16}$

The activation energy of diffusion $E_{D}$ was calculated using Eqn 5

$E_{D}=\left[R / \frac{1}{T_{1}}-\frac{1}{T_{2}}\right] \ln \left[\frac{D_{1}}{D_{2}}\right]$

Note that the difference in the temperatures of study for polyester and nylon is due to the type of fibre. For example, polyester is more crystalline in structure than nylon hence it requires higher temperatures for dyeing to take place. 

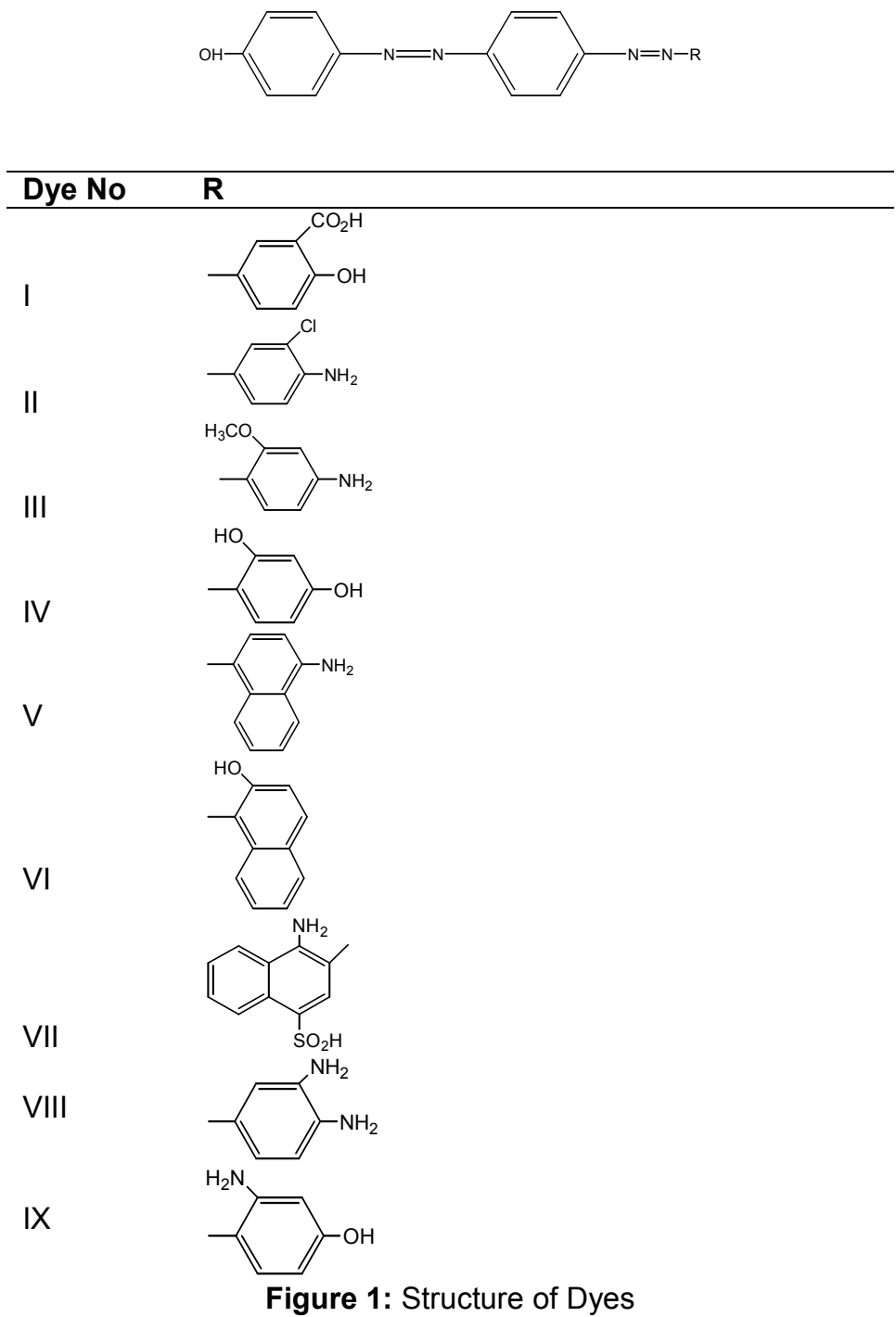

\section{RESULTS AND DISCUSSION}

Tables 1 and 2 show the results of thermodynamic studies including standard affinity, heat of dyeing and entropy of dyeing while figures 2 to 10 gives the rate curves of Dye I to IX correspondingly. The standard affinity of the dye samples decreased in magnitude with temperature, indicating that the migration of dye from the dyebath to the fibre was not enhanced. This is so because in most dye-fibre systems, the enthalpy of dyeing is negative. As a result, the magnitude of the standard affinity at $373 \mathrm{~K}$ was less than that at $363 \mathrm{~K}$ for the polyester dyeing system and also the magnitude of the standard affinity at $363 \mathrm{~K}$ was less than that at $353 \mathrm{~K}$ for the nylon 6 dyeing system. The standard heat of dyeing, $\Delta \mathrm{H}^{\circ}$, is of practical significance because it provides a quantitative description of the influence of temperature on dyeing equilibrium. The heat of dyeing is regarded as the sum of heats of formation of the various bonds, such as hydrogen bonds and ionic bonds, holding dye and fibre together. A decrease in the value of $\Delta \mathrm{H}^{\circ}$ means that more dye can be retained in the fibre, that is the interaction between dye and fibre is increased. 


\begin{tabular}{|c|c|c|c|c|}
\hline \multirow[b]{2}{*}{ Dye } & \multicolumn{2}{|c|}{$\Delta \mu^{\circ}(\mathrm{J} / \mathrm{mol})$ at } & \multirow[t]{2}{*}{$\Delta \mathrm{H}^{\mathrm{o}}(\mathrm{J} / \mathrm{mol})$} & \multirow[t]{2}{*}{$\Delta \mathrm{S}^{\circ}\left(\mathrm{JK}^{-1} / \mathrm{mol}^{-1}\right)$} \\
\hline & $363 \mathrm{~K}$ & $373 \mathrm{~K}$ & & \\
\hline I & -10953 & -10309 & -34333 & -64 \\
\hline II & -10938 & -7833 & -280603 & -311 \\
\hline III & -11877 & -4474 & -123671 & -740 \\
\hline IV & -10615 & -6674 & -153668 & -394 \\
\hline V & -10740 & -3430 & -276083 & -731 \\
\hline VI & -9007 & -8966 & -10482 & -4 \\
\hline VII & -1049 & -8640 & -77230 & -184 \\
\hline VIII & -9945 & -8683 & -55854 & -126 \\
\hline IX & -7536 & -4066 & -133500 & -347 \\
\hline
\end{tabular}

\begin{tabular}{|c|c|c|c|c|}
\hline & $\Delta \mu^{\circ}(\mathrm{J} / \mathrm{m}$ & & $\Delta \mathrm{H}^{\circ}(\mathrm{J} / \mathrm{mol})$ & $\Delta \mathrm{S}^{0}\left(\mathrm{JK}^{-1} / \mathrm{mol}^{-1}\right)$ \\
\hline Dye & $353 \mathrm{~K}$ & $363 \mathrm{~K}$ & & \\
\hline 1 & -10048 & -3803 & -230499 & -625 \\
\hline II & -10150 & -7071 & -118839 & -308 \\
\hline III & -11523 & -7549 & -151834 & -397 \\
\hline IV & -10446 & -8279 & -86939 & -217 \\
\hline V & -3925 & -2370 & -58833 & -136 \\
\hline VI & -10389 & -6625 & -72669 & -176 \\
\hline VII & -6026 & -1823 & -154391 & -420 \\
\hline VIII & -10259 & -8841 & -60308 & -142 \\
\hline IX & -11044 & -5803 & -196042 & -524 \\
\hline
\end{tabular}

When dye molecules migrate from the solution (or dispersion) to the fibre in a dyeing system, they become more ordered due to the confinement in the solid fibre phase. The results in Table 1 also show that the heat evolved on dyeing is quite high for both substrates and the dyes which gave decreased enthalpy of dyeing were more there compensated for by the corresponding increase in entropy. For instance, dye (II) in the polyester dye-fibre system gave a decreased enthalpy of $-9007 \mathrm{~J} / \mathrm{mol}$ but its entropy increased to $4 \mathrm{~J} / \mathrm{mol}$. 


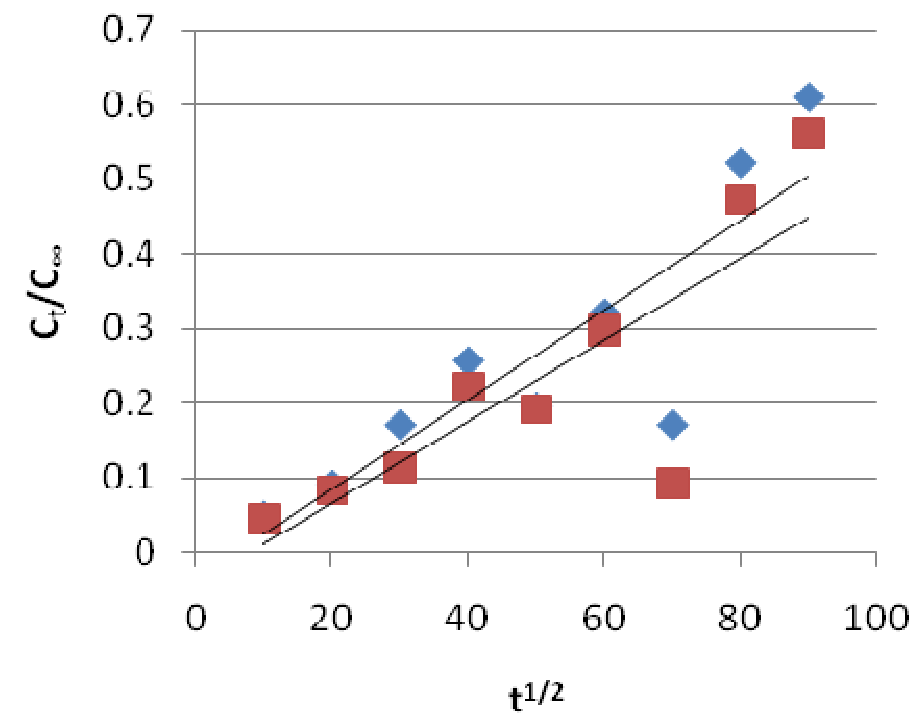

$+353 \mathrm{~K}$

- $343 \mathrm{~K}$

- Linear (353 K)

— Lined (343K)

Figure 2: Rate Curve of Dye I

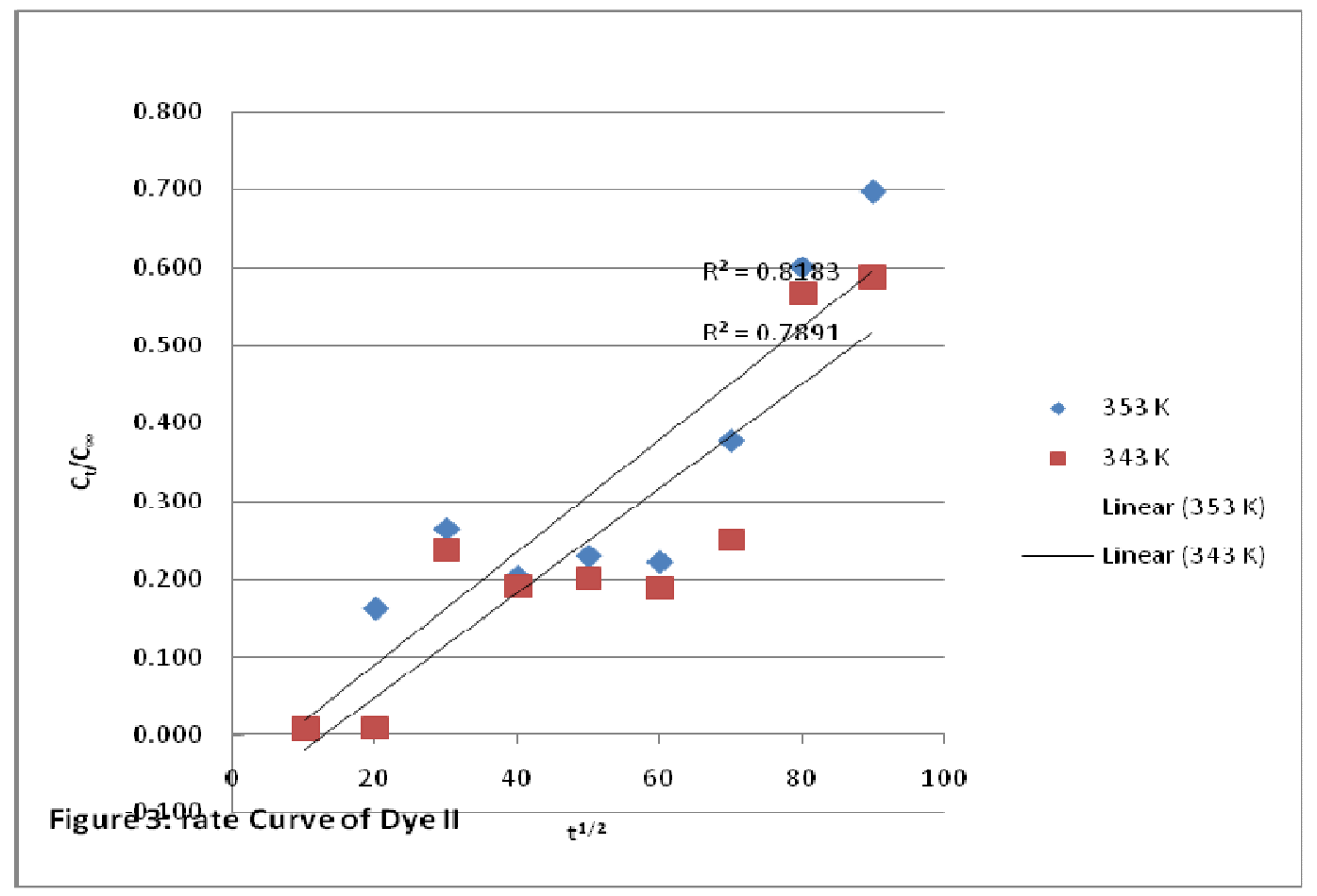



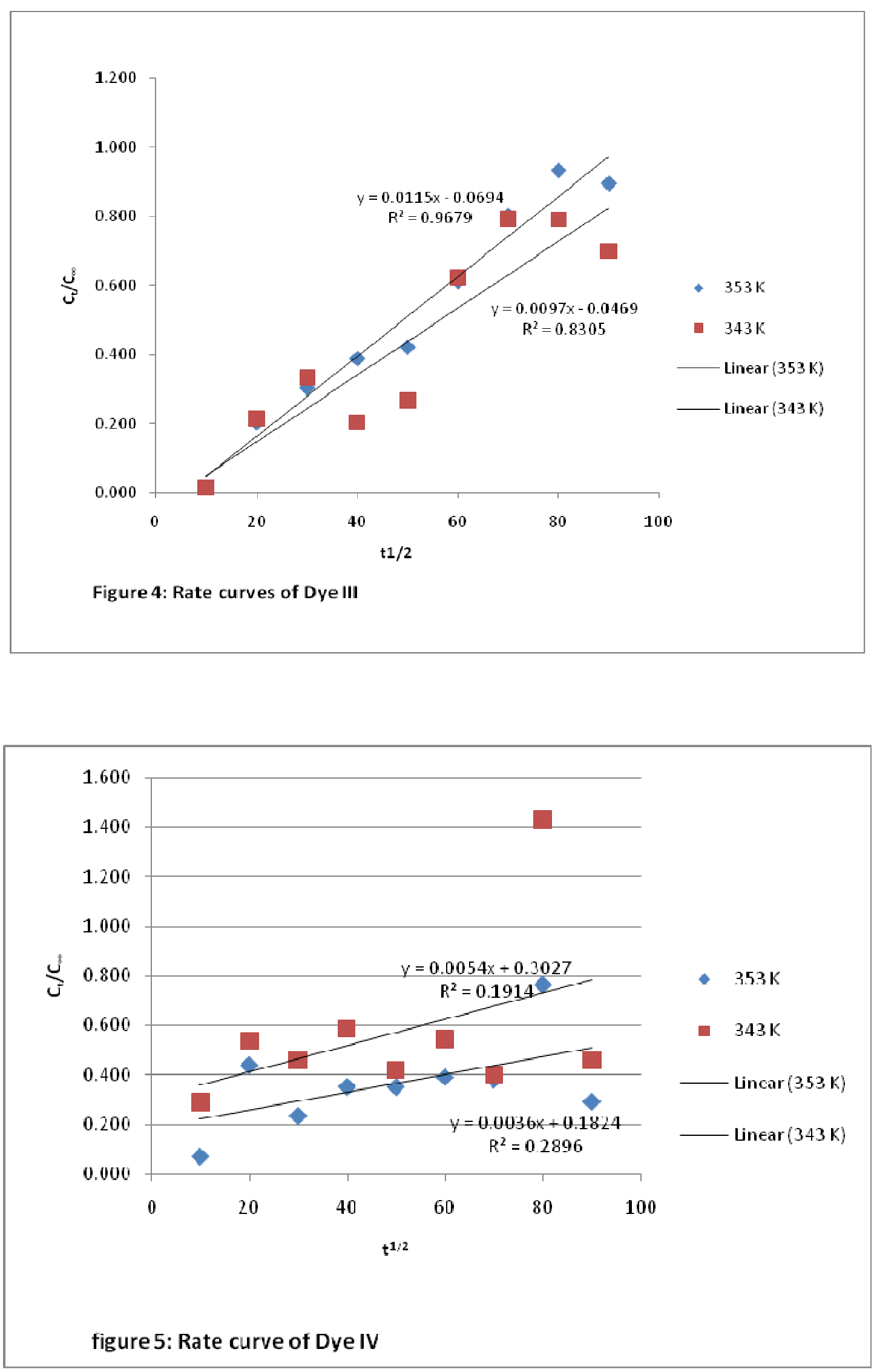

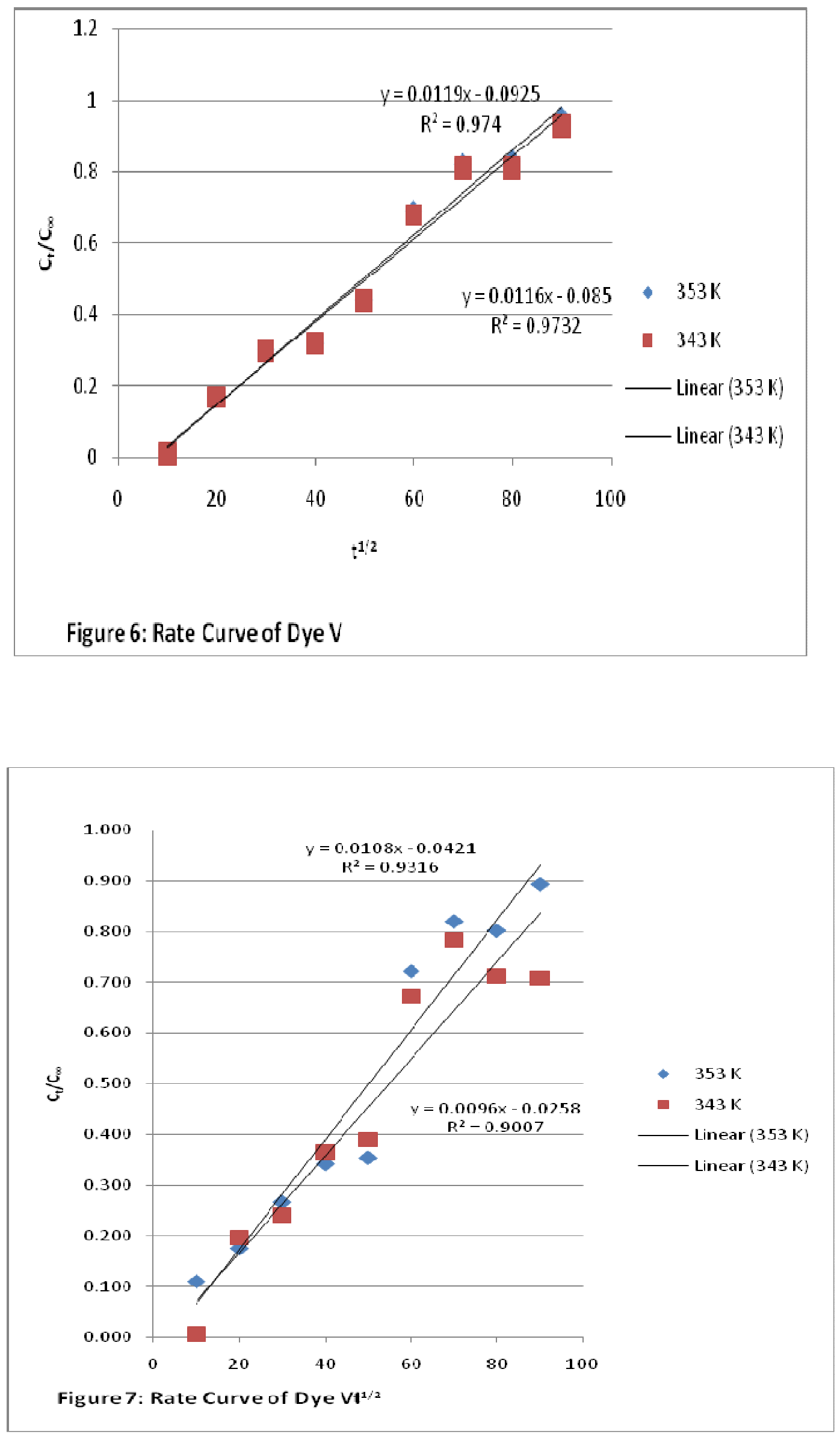


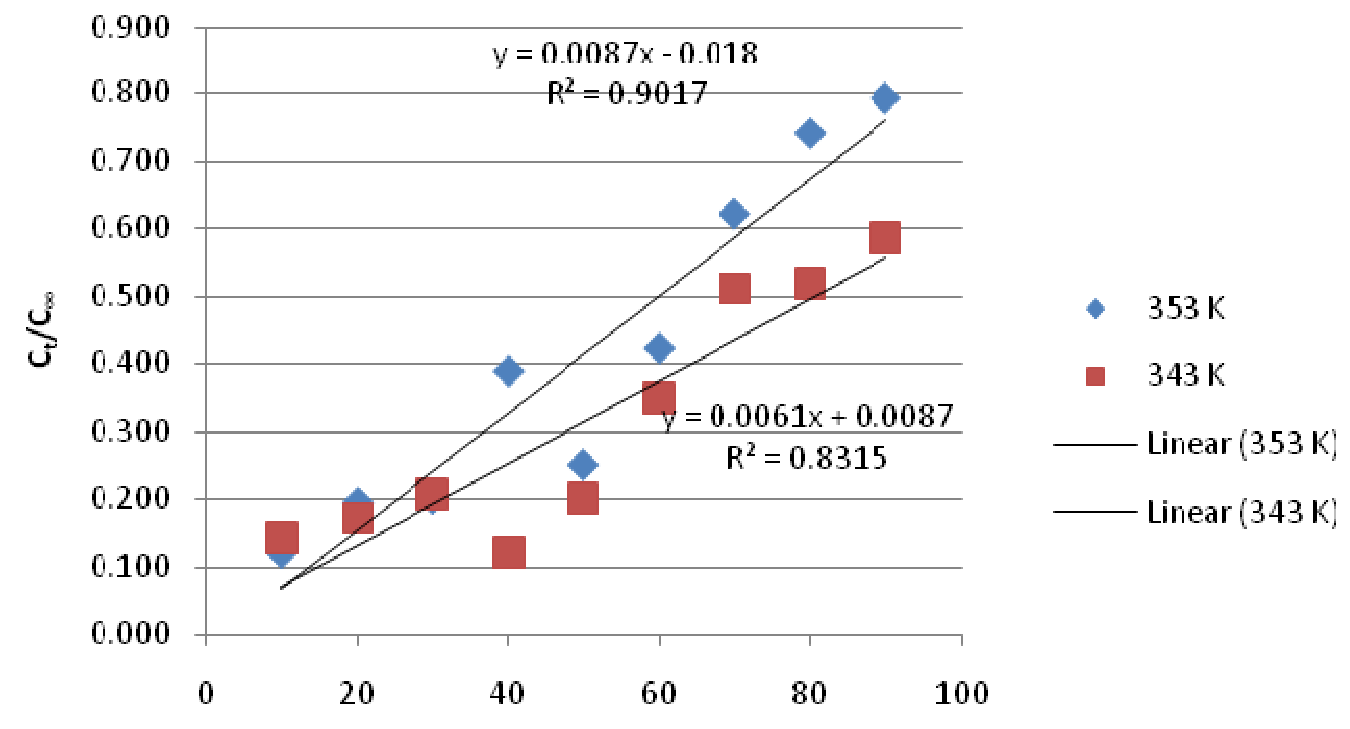

Figure 8: Rate Curve of Dye VII

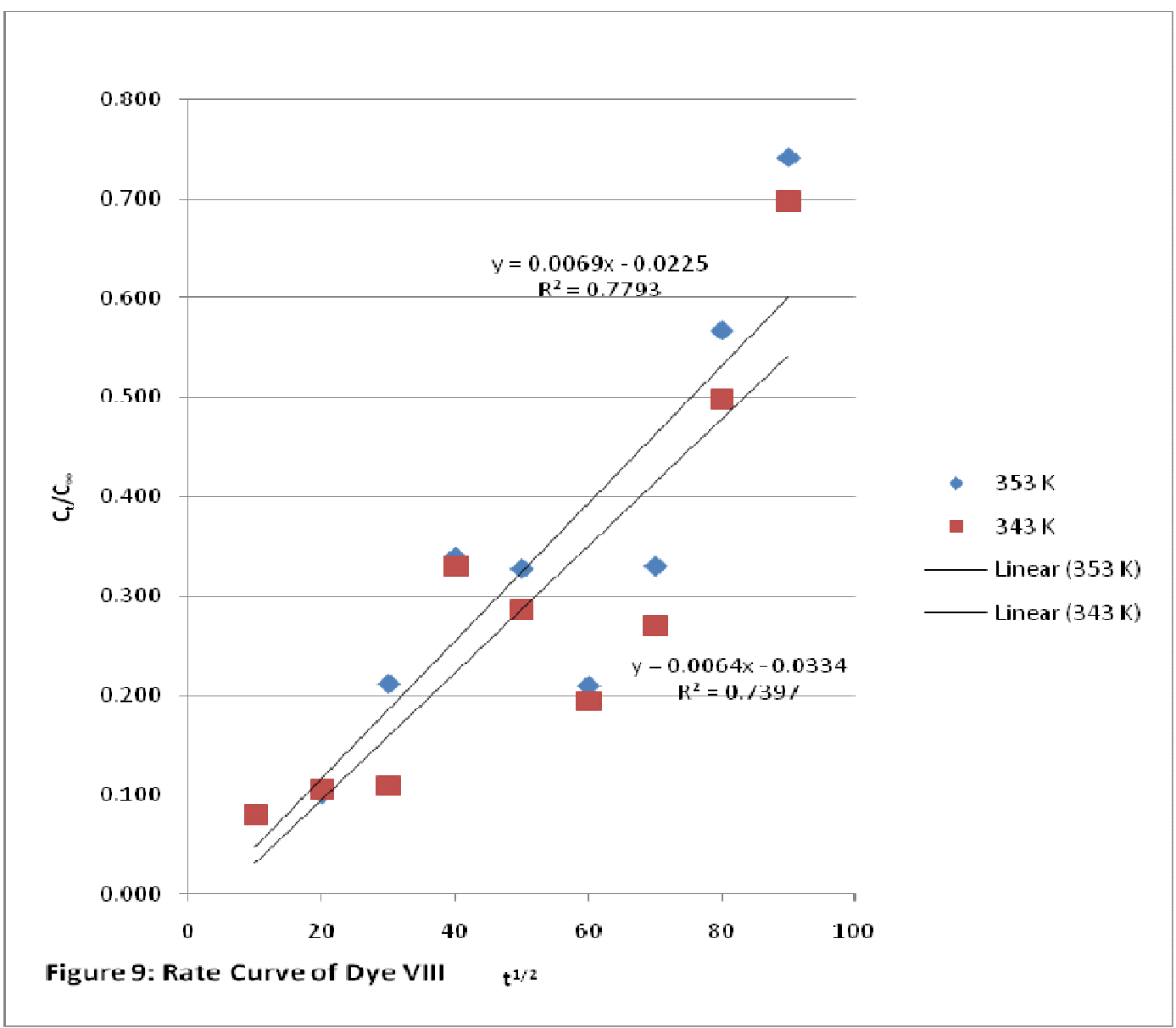




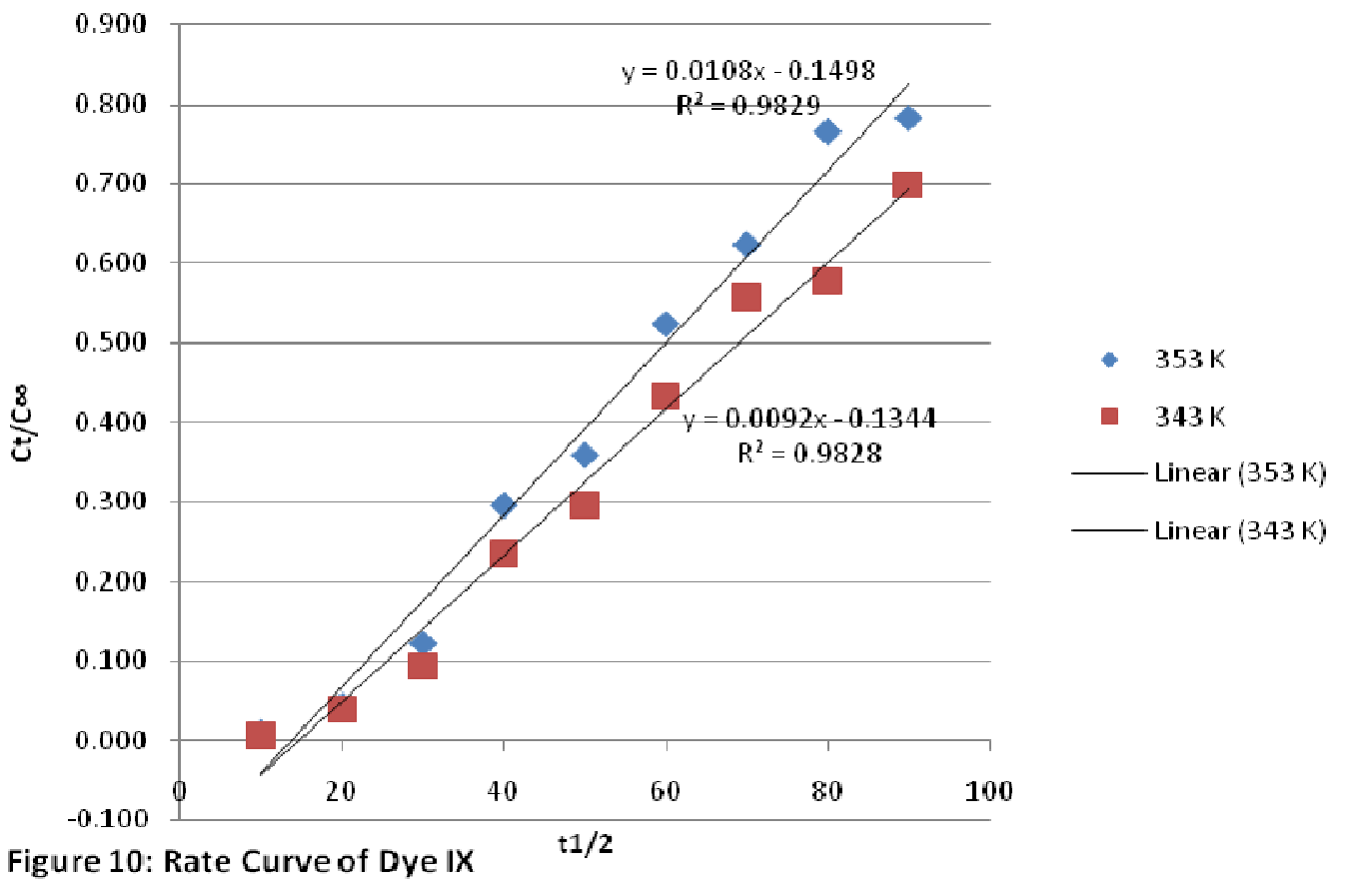

Similarly, in dye (V), the nylon 6 dye-fibre system gave a decreased heat of dyeing of $-58833 \mathrm{~J} / \mathrm{mol}$ and a corresponding increase in entropy of $-136 \mathrm{~J} / \mathrm{mol}$. This tends to corroborate the recent work done on the physico-chemical properties of monoazo dyes on synthetic-polymer-fibres (Otutu et al., 2007). However, the values of $\Delta \mu^{\circ}$ for the PET dye-fibre system are higher than those of the nylon 6 dye-fibre system except dyes (VI), (VII) and (IX). This suggests that the dyes have higher affinities for the polyester fibre than for the nylon 6 fibre.

The values found for the diffusion coefficient (Table 3) on nylon 6 fibre show that the higher the temperature, the higher the coefficient of diffusion. This indicates that at high temperatures, there is greater loosening up of the fibre structure, thus creating more spaces for easier diffusion of dye molecules. 
Activation energy of diffusion $\left(E_{D}\right)$

The values found for the activation energy of diffusion of each dye sample on nylon 6 fibre are given in Table iii. Here the values of $E_{D}$ reflect the amount of energy needed to assist the dye molecule in interring the fibre so as to overcome the surface barrier of the fibre. A small value means that the dye requires relatively little energy to overcome the surface barrier before entering the fibre while a larger value is the reverse ${ }^{3}$ it was also found that dye (I) has the highest value of $E_{D}$ followed by dye (VI) and (VII) respectively. These dye molecules must have entered the nylon 6 fibre with more difficulty than the others. This suggests that certain factors such as molecular weight can influence or affect dye diffusion and hence activation energy of diffusion. Comparing dyes (VI) and (VII) on molecular weight factor, it was observed that the latter has smaller value of activation energy of diffusion than the former as the molecular weight is lower. Similarly, dye (I) has higher activation energy of diffusion than dye (II) yet its molecular weight is lower. But this is not so when dyes (I) and (VI) are compared. For example, dye (I) has the highest activation energy of diffusion value of $97559 \mathrm{~J} / \mathrm{mol}^{-1}$ and molecular weight of 351.8 while dye $(\mathrm{VI})$ has a lower $E_{D}$ and yet its molecular weight is higher. This suggests that other intrinsic properties of the dye molecules such as planarity and molecular volume apart from molecular weight could be very important in analyzing activation energy of diffusion data. These agreed with that reported in the literatures (Yakubu, 2000; Venkataraman, 1974).

\section{CONCLUSION}

The dyeing properties of a series of disazo dyes were studied thermodynamically and kinetically on PET and nylon 6 substrates. In the thermodynamic study, it was found that the dyes generally have higher affinity values for the polyester fibre than for the nylon 6 fibre. On the other hand, there were changes in the $\Delta \mathrm{H}^{\circ}$ and $\Delta S^{\circ}$ in the two dye-fibre systems. The values of the $\Delta S^{\circ}$ were negative which do not favour dyeing. However, the $\Delta \mathrm{H}^{\circ}$ values were higher which suggests that it is the only driving force for dyeing to occur. The values of the $\Delta \mu^{\circ}$, $\Delta \mathrm{H}^{\circ}$, and $\Delta \mathrm{S}^{\circ}$ and also the presence of the $-\mathrm{OH}$ and $-\mathrm{NH}_{2}$ in the dye structures indicate that the hydrogen bonding mechanism is involved in the dye-fibre binding forces.

The values of activation energy of diffusion did not show any general trend, however, certain intrinsic properties of the dye molecules such as planarity and molecular volume could be more useful in interpreting activation energy of diffusion data for nylon 6 substrate. Further work in this area and that of the kinetics of PET fibre could prove to yield beneficial results.

\section{REFERENCES}

Abrahavt, E. V., 1977. Dyes and Their Intermediates. Edward Arnold (Pub.) Ltd: London.

Anna, U., Eva, B., Janka, O., Randovan, T. and Anton, M., 2007. Dyes and pigment, 72(2): $212-216$.

Bird, C. L. and Boston, W. S., 1975. The Theory of Coloration of Textiles. SDC: Bradford.

Giles, C. H., 1974. Laboratory course in Dyeing, SDC: Bradford, 139.

Kan, C. W., Chan K, Yuen, C. W. M. and Miao, M. H, 1998, Journal of Society of Dyers and Colourists 114, 61-65.

Kim, T., Son, Y., and Lim, Y., 2007. Dyes and pigments, $72(2): 246-250$.

Mcgregor, R., 1967. Journal of Society of Dyers and Colourists, 83(1): $57-58$.

Otutu, J. O., Okoro, D., Ossai, and E. K., 2008. J. Applied Sci., 8(2): 334 - 339.

Otutu, J. O., Ossai, E, K. and Jatto, E. O., 2007. J. Chem. Soc. Nig. 32(2): $81-99$.

Otutu, J. O., 2005. Ph. D Thesis, University of Benin, Benin City, Nigeria.

Peter, L., 1975. In The theory of Coloration of Textiles; Bird C L, Boston W S, eds.; SDC: Bradford, 181 $-225$.

Venkataraman, K., 1974. The chemistry of synthetic Dyes, Academic Press: New York.

Venkataraman, K., 1974. The chemistry of synthetic dyes, Academic press: New York, 131-132.

Yakubu, M. K., 2000. Ph.D Thesis, Ahmadu Bello University, Zaria, Nigeria. 